\title{
Low-density lipoprotein protects Vibrio vulnificus-induced lethality through blocking lipopolysaccharide action
}

\author{
Kwang-Hyun Park ${ }^{1 *}{ }^{\dagger}$, Jong-Suk Kim ${ }^{2 *}$, \\ Young-Rae Lee ${ }^{2}$, Young-Jae Moon ${ }^{2}$, \\ Hyun Hur ${ }^{2}$, Yun-Hee Choi ${ }^{2}$, \\ Cheon-Hyeon $\mathrm{Kim}^{2}$, Uh-Hyun Kim², \\ Eun-Kyung Song ${ }^{3}$, Wan-Hee Yoo ${ }^{4}$, \\ Chang-Seop Lee ${ }^{4}$, Byeong-Soo $\mathrm{Kim}^{5}$, \\ Sung-Ho Lee ${ }^{5}$, Phil-Youl Ryu ${ }^{6}$ \\ and Myung-Kwan $\mathrm{Han}^{3,7}$
}

\author{
${ }^{1}$ College of Pharmacy \\ Medicinal Resources Research Institute, Wonkwang University \\ Iksan 570-749, Korea \\ ${ }^{2}$ Department of Biochemistry, Institute of Medical Science \\ ${ }^{3}$ Department of Microbiology and Immunology \\ ${ }^{4}$ Department of Internal Medicine \\ Chonbuk National University Medical School \\ Jeonju 561-182, Korea \\ ${ }^{5}$ Department of Companion and Laboratory Animal Science \\ Kongju National University \\ Yesan 340-702, Korea \\ ${ }^{6}$ Genome Research Center for Enteropathogenic Bacteria \\ Department of Microbiology \\ Chonnam National University Medical School \\ Gwangju 501-746, Korea \\ ${ }^{7}$ Corresponding author: Tel, 82-63-270-3106; \\ Fax, 82-63-274-9833; E-mail, iamtom@ chonbuk.ac.kr \\ *These authors contributed equally to this work. \\ ${ }^{\dagger}$ Present address: Department of Biochemistry, Chonbuk National \\ University Medical School, Jeonju 561-182, Korea
}

Accepted 10 September 2007

Abbreviations: VVC, Vibrio vulnificus cytolysin

\begin{abstract}
Lipoprotein plays a role in the host defense against bacterial infection, and its serum level has been demonstrated to be an important prognosis factor of survival. We have previously demonstrated that LDL directly inactivates the hemolytic activity of Vibrio vulnificus cytolysin (VVC) in vitro. The object of this study was therefore to examine whether the LDL-mediated inactivation of VVC leads to protection against lethal infection of $V$. vulnificus in vivo, using wild and VVC-deficient $V$. vulnificus strains. Unexpectedly, we found that LDL protects mouse lethality induced by VVC-deficient as well as wild
\end{abstract}

V. vulnificus strain. We also demonstrated that LDL blocks $V$. vulnificus LPS-induced lethality in mice. These results suggest that $L D L$ preferentially act on endotoxin rather than exotoxin in the protection against V. vulnificus-induced mice lethality.

Keywords: endotoxemia; lipopolysaccharides; lipoproteins, LDL; Vibrio vulnificus; vvP protein, Vibrio vulnificus

\section{Introduction}

Bacterial constituents within human blood are involved in the generation of bacterial sepsis and septic shock, including exotoxin, endotoxin (LPS), peptidoglycans and lipoteichoic acid. Thus, scavengers of bacterial products are expected to protect against bacterial infection and sepsis, such as plasma lipoproteins (Canturk et al., 2002; Delgado-Rodriguez et al., 2002). Indeed, lipoproteins protect against the infection and inflammation by blocking endotoxin activity (Pajkrt et al., 1996; Netea et al., 1998). Furthermore, recently it has been known that total cholesterol, HDL and LDL levels on admission are inversely associated with the disease severity (Wu et al., 2004, Chien et al., 2005, Vermont et al., 2005). These findings suggest that lipoproteins play roles in the host defense against the bacterial infection, and its serum level is an important prognosis factor of survival. However, effect of lipoprotein on $V$. vulnificus infection is not clear.

$V$. vulnificus is known to be a life-threatening gram-negative pathogen that causes serious septicemia in human through the consumption of contaminated seafood such as oysters. V. vulnificus infection is characterized by the high fatality rates of $70 \%$ and the primary attack against people who are immunocompromised or have underlying diseases such as liver cirrhosis (Canturk et al., 2002). V. vulnificus cytolysin (VVC) has been incriminated as a virulence factors in $V$. vulnificus infection (Pajkrt et al., 1996). Indeed, antibodies against the cytolysin were detected in the blood of $\checkmark$. vulnificus infected mice or a human that survive V. vulnificus disease (Gray and Kreger, 1986). These results suggest that VVC might be importantly involved in the pathogenesis of $V$. vulnificus infection. Thus, inactivation of VVC could be impor- 
tant to survival of $V$. vulnificus-infected host.

LDL induces the inactivation of Staphylococcus aureus $\alpha$-toxin (Bhakdi et al., 1983). Furthermore, we also found that LDL inactivates VVC hemolytic activity in vitro (Kim and Kim, 2002, Park et al., 2005). These findings suggest that LDL could prevent the toxicity of $\mathrm{VVC}$ and lead to survival of mice infected by $V$. vulnificus. Therefore, we aim to examine whether the LDL-mediated inactivation of VVC leads to protection against the lethal infection of $V$. vulnificus in vivo, using wild and VVCdeficient $V$. vulnificus strains.

\section{Materials and Methods}

\section{Mice}

Female ICR mice, 25 to $28 \mathrm{~g}$ weights, 6 to 7 weeks old, were obtained from the Orient Bio Inc. (Korea), were acclimated to the Chonbuk National University Medical School Facility for 5 days and fed libitum with regular chow. All experimental animals used in this study were under a protocol approved by the Institutional Animal Care and Use Committee of the Chonbuk National University. Mice were intraperitoneally injected with cultured $V$. vulnificus $\left(2 \times 10^{8}\right.$ colony forming unit $\left.(\mathrm{CFU}) / \mathrm{mouse}, 0.1 \mathrm{ml}\right)$ as described by Lee et al. (2004). Mice were pre-injected with an $0.1 \mathrm{ml}$ of saline or LDL-saline solution $2 \mathrm{~h}$ before the bacterial injection and monitered for $72 \mathrm{~h}$ for their mortality.

\section{Bacterial strain and culture}

Two strains of $V$. vulnificus, MO6-24/O (wild strain) and CVD 707 (VVC-deficient strain) were kindly supplied by the University of Maryland School of Medicine (Wright and Morris, 1991). Both strains were cultured in brain heart infusion (BHI) broth as described by Kreger et al. (1988). The bacteria were precultured at $37^{\circ} \mathrm{C}$ for $4 \mathrm{~h}$ in $\mathrm{BHI}$ broth $(\mathrm{BD}$, Franklin Lakes, $\mathrm{NJ}$ ) by picking one colony from the bacteria-cultivated TCBS agar plate (BD, Franklin Lakes, NJ). The stabilized bacteria were transferred to ten volume of new $\mathrm{BHI}$ broth, then further cultured with shacking at $37^{\circ} \mathrm{C}$ for $4 \mathrm{~h}$. The bacteria numbers were calculated by measurement of turbidity with a spectrophotometer (DU530, Beckman, Fullerton, CA).

\section{LDL preparation}

LDL was isolated from human plasma by the method of Koo et al. (2000). Briefly, serum was obtained from bloods of normal healthy adults by a centrifugation at $1,200 \times g$ for $10 \mathrm{~min}$. Lipoproteins were purified by sequential preparative ultra centrifugations of serum in the presence of EDTA and protease inhibitors as preservatives. After a centrifugation of serum at $100,000 \times g$ for $20 \mathrm{~h}$ at $15^{\circ} \mathrm{C}$ in swing bucket rotor (SW 41Ti, Beckman, Fullerton, CA), the top layer of VLDL was removed with a Pasteur pipette. The pellets in the infranatant were resuspended and adjusted to the density of $1.063 \mathrm{~g} / \mathrm{ml}$ by $\mathrm{NaBr}$. The LDL fraction was obtained by a centrifugation of infranatant at $100,000 \times g$ for $24 \mathrm{~h}$ at $15^{\circ} \mathrm{C}$. The LDL was extensively dialyzed against PBS.

\section{V. vulnificus LPS preparation}

$V$. vulnificus was grown in $\mathrm{BHI}$ broth containing $1 \%$ $\mathrm{NaCl}$ at $37^{\circ} \mathrm{C}$ and harvested by a centrifugation at $10,000 \times g$ for $30 \mathrm{~min}$. The cells were washed with deionized water three times and soaked overnight in acetone. The cells were then centrifuged, washed twice with acetone, and dried at room temperature. LPS was prepared from the acetonedried cells by the method of Bahrani and Oliver (1991). Briefly, $5 \mathrm{~g}$ of acetone-dried cells were suspended in equal volumes of preheated $\left(69^{\circ} \mathrm{C}\right)$ water and $90 \%$ phenol and the mixture was stirred for $15 \mathrm{~min}$. After cooling on ice, the mixture was centrifuged at $10,000 \times \mathrm{g}$. The aqueous phase was collected and extracted three times. The aqueous phases were pooled and dialyzed against deionized water for 3 to 5 days and then lyophilized. The fluffy powder, dissolved in $50 \mathrm{mM}$ Tris- $\mathrm{HCl}, \mathrm{pH} 7.0$, was treated with bovine pancreatic RNase $(40 \mu \mathrm{g} / \mathrm{ml})$ and DNase I $(100 \mu \mathrm{g} / \mathrm{ml})$ at $37^{\circ} \mathrm{C}$ for $1 \mathrm{~h}$. Then, proteinase $\mathrm{K}(10 \mu \mathrm{g} / \mathrm{ml})$ was added and the reaction mixture was incubated at $60^{\circ} \mathrm{C}$ for $1 \mathrm{~h}$. The mixture was repeatedly ultracentrifuged at $105,000 \times g$ for $2 \mathrm{~h}$ until the optical density of the supernatant was less than 0.01 at 260 and $280 \mathrm{~nm}$. The purified LPS was dissolved in water and lyophilized. LPS was dissolved in a saline solution and dispersed by brief sonication.

\section{Serological analysis}

Blood clinical data were obtained from the Chonbuk National University Hospital. The informed consent was obtained. The blood samples were analyzed for total cholesterol, HDL-cholesterol, LDLcholesterol, and triglycerides using an automatic blood analyzer (Hitachi, Tokyo, Japan).

\section{Statistical Analysis}

All experimental data are mean \pm SD. Statistical analysis was performed using ANOVA test, Rank 
Table 1. Lipid profiles in patients with V. vulnificus infection.

\begin{tabular}{lccc}
\hline & Lived & Dead & $P$ value \\
\hline Number & 4 & 11 & \\
Sex (Male/Female) & $4 / 0$ & $7 / 4$ & 0.65 \\
Age & $55.0 \pm 16.3$ & $71.7 \pm 15.7$ & 0.0001 \\
Total cholesterol $(<200 \mathrm{mg} / \mathrm{dl})$ & $190.8 \pm 40.0$ & $64.8 \pm 76.7$ & 0.26 \\
Triglyceride $(<200 \mathrm{mg} / \mathrm{dl})$ & $124.7 \pm 63.3$ & $20.4 \pm 8.12$ & 0.38 \\
HDL-cholesterol $(48.9-73.5 \mathrm{mg} / \mathrm{dl})$ & $26.3 \pm 13.6$ & $35.6 \pm 13.9$ & 0.0001 \\
LDL-cholesterol $(<130 \mathrm{mg} / \mathrm{dl})$ & $155.3 \pm 40.7$ & &
\end{tabular}

Data were presented as mean $\pm \mathrm{SD}$.

and Student's $t$ test, and $P<0.05$ was considered to be significant.

\section{Results}

We first analyzed relationship between the severity of $V$. vulnificus-infected patients and serum levels of LDL cholesterol (LDLC). To assess initial serum levels of LDLC and their correlations with the clinical outcome for patients with $V$. vulnificus infection, we performed a retrospective study against patients $(n=16)$ diagnosed as $V$. vulnificus septicemia in the Chonbuk National University Hospital (Table 1). Death cases $(n=12)$ showed lower serum levels of LDLC compared to normal patients $(35.6 \pm 13.9 ; P<0.0001$, normal, $<130$ $\mathrm{mg} / \mathrm{dl})$, but survival cases $(n=4)$ showed higher levels compared to death cases and similar serum levels to normal patients $(155.3 \pm 40.7 ; \quad P<$ $0.0001)$. Moreover, total cholesterol of death cases (71.7 $\pm 15.7 ; P<0.0001$, normal, $<200 \mathrm{mg} / \mathrm{dl})$ was also lower than those of survival cases (190.8 $\pm 40.0)$. These results suggest that the fatality of human $V$. vulnificus infection is reciprocally correlated with serum total cholesterol and LDLC.

Many studies suggested that VVC might be a virulence factor for $V$. vulnificus infection. We demonstrated that LDL inactivates the hemolytic activity of VVC in vitro. Thus, we hypothesized that the lower survival in $V$. vulnificus infected patients with lower LDLC is due to lower LDL-mediated inactivation of VVC. To demonstrate this, we examined the protective effect of LDL preinjection against the lethality of mice infected with wild and VVC-deficient $V$. vulnificus strains. We first confirmed that VVC-deficient $V$. vulnificus could not produce VVC in the culture supernatant by western blotting (Figure 1). We also examined whether exogenous LDL injection increases LDL serum level. A single peritoneal injection of LDL increased serum LDL level 1.5 times at a dose of $10 \mathrm{mg} / \mathrm{kg}$ LDL and two times at a dose of $50 \mathrm{mg} / \mathrm{kg}$ LDL $2 \mathrm{~h}$ after the injection compared to an injection of

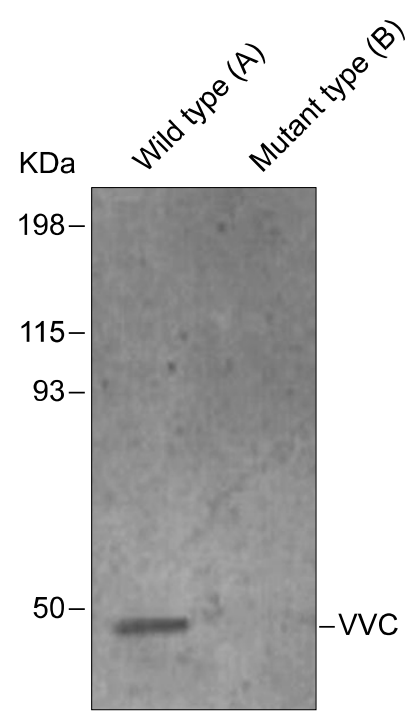

Figure 1. No production of $V$. vulnificus cytolysin in VVC knockout $V$. vulnificus (CVD707). Wild type V. vulnificuse (MO6-24/O) (A) and VVC knockout V. vulnificus (CVD707) (B) were cultured for $4 \mathrm{~h}$ in brain heart infusion broth as described in Material and Methods. The culture supernatant was concentrated with ammonium sulfate and analyzed by western blot with anti-VVC antibody.

saline (Figure 2A). Wild $\mathrm{V}$. vulnificus infection by a single injection of $2 \times 10^{8} \mathrm{CFU}$ induced death of all mice within $60 \mathrm{~h}$ from the injection. A single injection of LDL (10 and $50 \mathrm{mg} / \mathrm{kg}$ ) before the infection significantly increased survival rate in a dose dependent manner. Especially, more than $80 \%$ mice survived the infection in $50 \mathrm{mg} / \mathrm{kg}$ LDLpretreated group $(n=5)$ (Figure 2B). The difference of virulence of WT and VVC mutant was not obvious in the presence of LDL (Figure 2C). This finding is consistent with a previous report showing that VVC expression from $V$. vulnificus is not correlated to the lethality of infected mice (Wright and Morris, 1991), suggesting that LDL-mediated inactivation of VVC is not a cause for the protective effect of LDL against $V$. vulnificus infection.

We next focused on which virulent constituent is blocked by LDL. LPS is a substance of outer- 
A

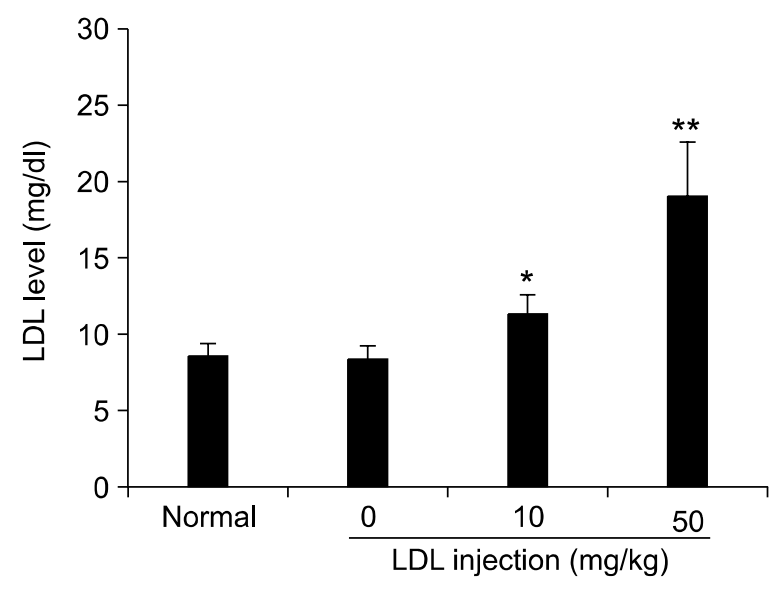

C

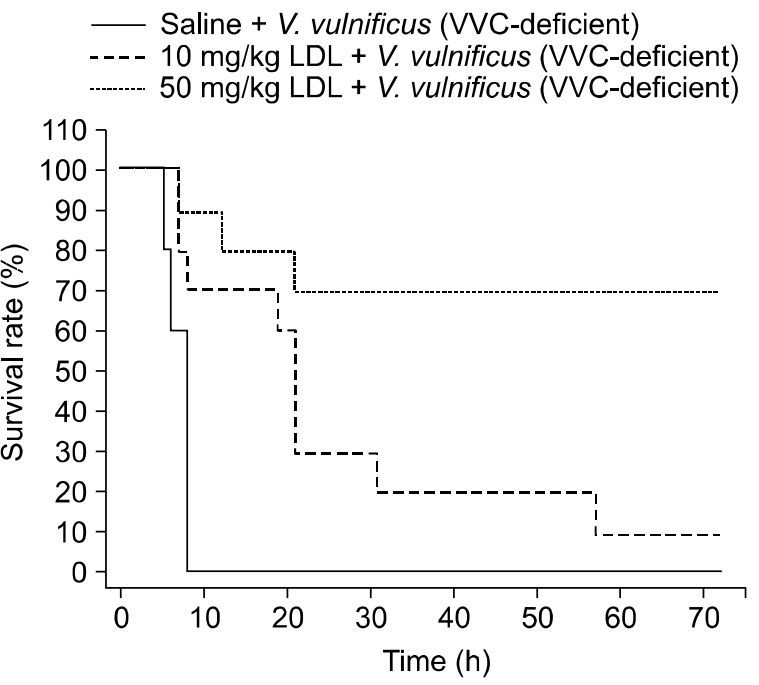

membrane in gram-negative bacterium and can induce endotoxemia (Parker et al., 1995). Thus, we purified LPS from $V$. vulnificus and examined whether LDL pretreatment protects $V$. vulnificus LPS-induced lethality. A single injection of purified LPS $(20 \mathrm{mg} / \mathrm{kg})$ from $V$. vulnificus induced $100 \%$ lethality within $50 \mathrm{~h} \mathrm{(12} \mathrm{mice} \mathrm{died} \mathrm{out} \mathrm{of} \mathrm{a} \mathrm{total} \mathrm{of}$ 12). A single injection of LDL (10 and $50 \mathrm{mg} / \mathrm{kg}$ ) before LPS injection significantly delayed $V$. vulnificus LPS-induced lethality in a dose dependent manner (Figure 3). These data suggest that LDL prevents the toxicity of $V$. vulnificus LPS and inhibits the lethality induced by $V$. vulnificus LPS.

\section{Discussion}

It has been known that serum levels of lipid,
B

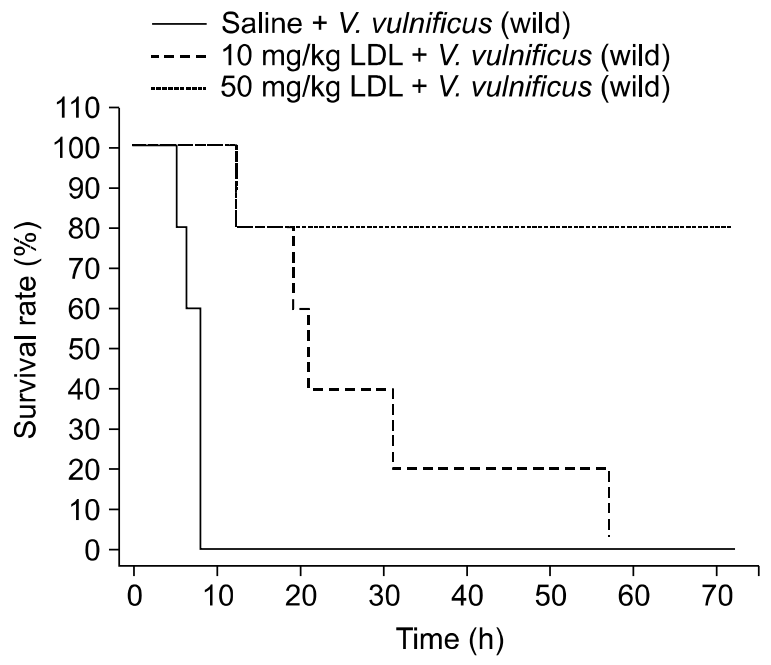

Figure 2. Effect of $L D L$ preinjection on the lethality induced by wild (B) and VVC deficient (C) V. vulnificus strains. LDL (10 and $50 \mathrm{mg} / \mathrm{kg}$ ) was intraperitoneally injected to mice. Two $h$ later, serum LDL levels was measured as described in Materials and Methods (A). Error bars, s.d.; $n=5$ in each group. ${ }^{*} P<0.002,{ }^{* *} P<0.005$, compared with saline group. Two $\mathrm{h}$ after LDL injection, wild type (MO6-24/0) and VVC knockout V. vulnificus (CVD707) $\left(2 \times 10^{8} \mathrm{CFU}\right.$ in $\left.0.1 \mathrm{ml}\right)$ was intravenously injected. Survival was determined during the 3 day period after injection, after which there was no further loss of animal life. The survival rate of the group treated with LDL is significantly different from the survival rate of the control group ( $P<0.001$ by the log rank test).

lipoproteins, and lipoprotein-associated proteins are significantly changed in patients with sepsis (Barlage et al., 2001; Pussinen et al., 2001; Carpentier and Scruel, 2002; Khovidhunkit et al., 2004). Total cholesterol, HDL, and LDL are reduced in serum of patients with sepsis and in contrast, plasma triglyceride is elevated (Fraunberger et al., 1999; Pussinen et al., 2001; Kitchens et al., 2003; van Leeuwen et al., 2003; Khovidhunkit et al., 2004). In this study, we observed that levels of total cholesterol, triglyceride and LDL is reduced but level of HDL is relatively unchanged in patient with $V$. vulnificus sepsis, which shows a different serum profile of lipid from other sepsis. Especially, LDL level is remarkably reduced in serum of patient with $V$. vulnificus sepsis.

We also observed a positive effect of LDL supplement at septicemia induced by $V$. vulnificus 


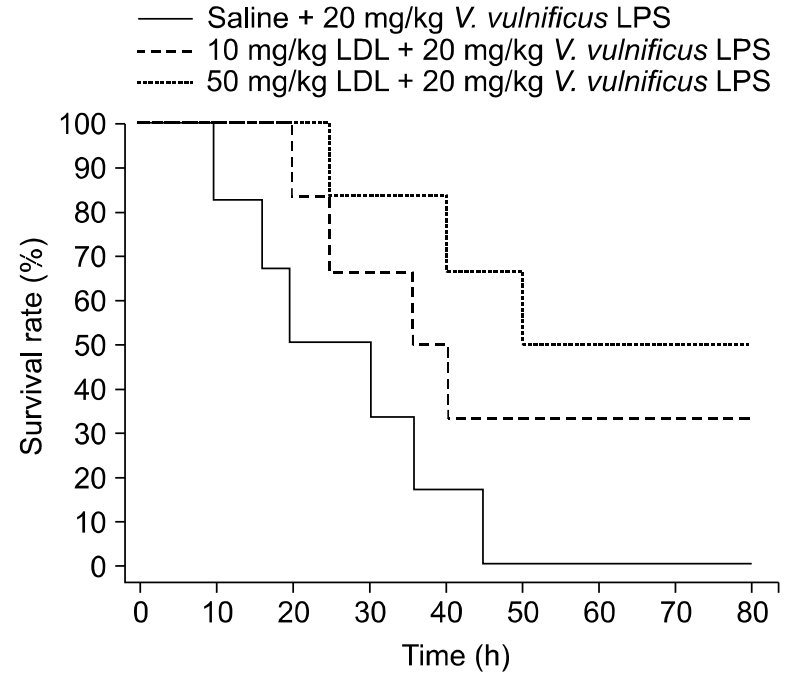

Figure 3. Effect of LDL preinjection on lethality induced by purified $V$. vulnificus LPS. LDL (10 and $50 \mathrm{mg} / \mathrm{kg}$ ) or saline was injected to mice, intraperitoneally. Two $\mathrm{h}$ after, LPS $(20 \mathrm{mg} / \mathrm{kg})$ was intraperitoneally infused. Survival was determined during indicated time period after injection. The survival rates of groups treated with 10 and $50 \mathrm{mg} / \mathrm{kg}$ of LDL are significantly different from the survival rate of the control group $(P<0.05$ and $P<0.01$, respectively, by log rank test).

infection in an animal model. This finding suggests that LDLC has a defense mechanism in host with $V$. vulnificus infection. This is consistent with a previous report that the improvements in morbidity and mortality obtained by intensive insulin therapy in critically ill patients are partially attributable to increases in the serum levels of LDL and HDL lipoproteins. The changes in septic patient lipid profile is mediated by peroxisome proliferatorsactivated receptors (PPARs) (Beigneux et al., 2000; Vanttinen et al., 2005). Indeed, a PPAR agonist improved survival in an animal model of enotoxemia (Liu et al., 2005). Thus PPAR agonists seem to be an attractive therapeutic tool for $V$. vulnificus sepsis, which is needed for further study.

\section{Acknowledgements}

This work was supported by grants of the Korea Science and Engineering Foundation (M10528010003-05N280100310 and R11-2002-100-02007-0) and the grant of PostDoc. Program, Chonbuk National University (EK Song).

\section{References}

Bahrani KF, Oliver JD. Electrophoretic analysis of lipopolysaccharide isolated from opaque and translucent colony variants of Vibrio vulnificus using various extraction methods. Microbios 1991;66:83-93
Barlage S, Frohlich D, Bottcher A, Jauhiainen M, Muller HP, Noetzel F, Rothe G, Schutt C, Linke RP, Lackner KJ, Ehnholm C, Schmitz G. ApoE-containing high density lipoproteins and phospholipid transfer protein activity increase in patients with a systemic inflammatory response. J Lipid Res 2001;42: 281-90

Beigneux AP, Moser AH, Shigenaga JK, Grunfeld C, Feingold KR. The acute phase response is associated with retinoid $X$ receptor repression in rodent liver. J Biol Chem 2000;275:16390-9

Bhakdi S, Tranum-Jensen J, Utermann G, Fussle R. Binding and partial inactivation of Staphylococcus aureus $\alpha$-toxin by human plasma low density lipoprotein. J Biol Chem 1983; 258:5899-904

Canturk NZ, Canturk Z, Okay E, Yirmibesoglu O, Eraldemir $B$. Risk of nosocomial infections and effects of total cholesterol, HDL cholesterol in surgical patients. Clin Nutr 2002;21:431-6

Carpentier YA, Scruel O. Changes in the concentration and composition of plasma lipoproteins during the acute phase response. Curr Opin Clin Nutr Metab Care 2002;5:153-8

Chien JY, Jerng JS, Yu CJ, Yang PC. Low serum level of high-density lipoprotein cholesterol is a poor prognostic factor for severe sepsis. Crit Care Med 2005;33:1688-93

Delgado-Rodriguez M, Medina-Cuadros M, Gomez-Ortega A, Martinez-Gallego G, Mariscal-Ortiz M, MartinezGonzalez MA, Sillero-Arenas M. Cholesterol and serum albumin levels as predictors of cross infection, death, and length of hospital stay. Arch Surg 2002;137:805-12

Fraunberger P, Schaefer S, Werdan K, Walli AK, Seidel D. Reduction of circulating cholesterol and apolipoprotein levels during sepsis. Clin Chem Lab Med 1999;37:357-62

Gray LD, Kreger AS. Detection of anti-Vibrio vulnificus cytolysin antibodies in sera from mice and a human surviving V. vulnificus disease. Infect Immun 1986;51:964-5

Khovidhunkit W, Kim MS, Memon RA, Shigenaga JK, Moser $\mathrm{AH}$, Feingold KR, Grunfeld C. Effects of infection and inflammation on lipid and lipoprotein metabolism: mechanisms and consequences to the host. J Lipid Res 2004; 45:1169-96

Kim BS, Kim JS. Cholesterol induce oligomerization of Vibrio vulnificus cytolysin specifically. Exp Mol Med 2002;34: 239-42

Kitchens RL, Thompson PA, Munford RS, O'Keefe GE. Acute inflammation and infection maintain circulating phospholipid levels and enhance lipopolysaccharide binding to plasma lipoproteins. J Lipid Res 2003;44:2339-48

Koo BS, Lee DS, Yang JY, Kang MK, Sohn HS, Park JW. Lipoprotein lipase-mediated uptake of glycated LDL. J Biochem Mol Biol 2000;33:148-54

Kreger AS, Kothary MH, Gray LD. Cytolytic toxins of Vibrio vulnificus and Vibrio damsela. Methods Enzymol 1988; 165:176-89

Lee YR, Park KH, Lin ZZ, Kho YJ, Park JW, Rho HW, Koo BS, Kim HR, Song EK, Yu HN, Han MK, Lee SO, Jhee EC, Kim JS. A calcium-calmodulin antagonist blocks experi- 
mental Vibrio vulnificus cytolysin-induced lethality in an experimental mouse model. Infect Immun 2004;72:6157-9

Liu D, Zeng BX, Zhang SH, Yao SL. Rosiglitazone, an agonist of peroxisome proliferator-activated receptor $\gamma$, reduces pulmonary inflammatory response in a rat model of endotoxemia. Inflamm Res 2005;54:464-70

Netea MG, de Bont N, Demacker PN, Kullberg BJ, Jacobs LE, Verver-Jansen TJ, Stalenhoef AF, Van der Meer JW. Lipoprotein(a) inhibits lipopolysaccharide-induced tumor necrosis factor $\alpha$ production by human mononuclear cells. Infect Immun 1998;66:2365-7

Pajkrt D, Doran JE, Koster F, Lerch PG, Arnet B, van der Poll $\mathrm{T}$, ten Cate JW, van Deventer SJ. Antiinflammatory effects of reconstituted high-density lipoprotein during human endotoxemia. J Exp Med 1996;184:1601-8

Park KH, Yang HB, Kim HG, Lee YR, Hur H, Kim JS, Koo BS, Han MK, Kim JH, Jeong YJ, Kim JS. Low density lipoprotein inactivates Vibrio vulnificus cytolysin through the oligomerization of toxin monomer. Med Microbiol Immunol 2005;194:137-41

Parker TS, Levine DM, Chang JC, Laxer J, Coffin CC, Rubin AL. Reconstituted high-density lipoprotein neutralizes gramnegative bacterial lipopolysaccharides in human whole blood. Infect Immun 1995;63:253-8
Pussinen PJ, Metso J, Malle E, Barlage S, Palosuo T, Sattler W, Schmitz G, Jauhiainen $M$. The role of plasma phospholipid transfer protein (PLTP) in HDL remodeling in acute-phase patients. Biochim Biophys Acta 2001;1533: 153-63

van Leeuwen HJ, Heezius EC, Dallinga GM, van Strijp JA, Verhoef $\mathrm{J}$, van Kessel KP. Lipoprotein metabolism in patients with severe sepsis. Crit Care Med 2003;31:1359-66

Vanttinen M, Nuutila P, Kuulasmaa T, Pihlajamaki J, Hallsten K, Virtanen KA, Lautamaki R, Peltoniemi P, Takala T, Viljanen AP, Knuuti J, Laakso M. Single nucleotide polymorphisms in the peroxisome proliferator-activated receptor $\delta$ gene are associated with skeletal muscle glucose uptake. Diabetes 2005; $54: 3587-91$

Vermont CL, den Brinker M, Kakeci N, de Kleijn ED, de Rijke YB, Joosten KF, de Groot R, Hazelzet JA. Serum lipids and disease severity in children with severe meningococcal sepsis. Crit Care Med 2005;33:1610-5

Wright AC, Morris JG, Jr. The extracellular cytolysin of Vibrio vulnificus: inactivation and relationship to virulence in mice. Infect Immun 1991;59:192-7

Wu A, Hinds CJ, Thiemermann C. High-density lipoproteins in sepsis and septic shock: metabolism, actions, and therapeutic applications. Shock 2004;21:210-21 